\title{
A MODEL TO INTEGRATE ISLAMIC PERSPECTIVE INTO STANDARD SCHOOL TEXTBOOKS
}

\author{
${ }^{1}$ MOHD ABDUL ALAM, ${ }^{2}$ PROF. DR. DAWOOD A. AL-HIDABI, \\ ${ }^{3}$ PROF DR. ISMAIL B. S. AHMAD
}

\begin{abstract}
${ }^{1}$ Doctoral Candidate, Department of Curriculum and Instruction, Kulliyyah of Education, International Islamic University Malaysia

${ }^{2}$ Department of Social Foundation and Educational Leadership, Kulliyyah of Education, International Islamic University Malaysia

${ }^{3}$ Department of Language and Literacy, Kulliyyah of Education, International Islamic University Malaysia.
\end{abstract}

\begin{abstract}
This article seeks to provide a proposed model of integrating Islamic Perspective into the Cambridge University issued Global Perspectives textbook, hereto referred as "GP" textbook used in the, "The Next Generation School", hereto referred as "TNG" in Qatar. Before introducing the proposed model, theoretical integration models from Al-Alwani (1989) to operational integration models by Al-Hidabi (2019) are studied and its modifications adopted for the proposed model. Selected Western models of integration are analysed and where needed incorporated into the proposed integration model. After explaining the conceptual frame work of the proposed integration model, its related components, standards, criteria and processes are also presented with examples from the GP textbook where two chapters are integrated with Islamic Perspective using the integration model.
\end{abstract}

Keywords: Islamisation; Integration of Islamic Perspective; Integration; Education; Social Studies

\section{INTRODUCTION}

In an earlier article titled, "Reflections on attempts towards integrated Islamic Curriculum and Integration of Islamic Perspective" the authors had presented amongst other things models of integrating Islamic Perspective into standard textbooks. In particular four models were studied and analysed which are Eclectic Model(Hassan, 1989), Ulu Al-Albaab Model, (Hassan, 2010), 
International Journal of Arts and Humanities

ISSN: 2581-3102

Volume: 04, Issue: 07 "July 2020"

QMIKE Model(Baba et al, 2013) and Al-Hidabi Model(2019). This article will present selected western models of integration following which a proposed mother model of integrating Islamic Perspective will be introduced that incorporates Islamic and Western models of integration. A smaller version of the mother model, the child model will then be proposed and two chapters from the Cambridge University issued GP textbook will be integrated with Islamic Perspective using the proposed Child Model.

\section{Western Models of Integration}

Curriculum Integration definitions are various, ambiguous and the boundary lines between different forms of integration often get blurred (Nesin \& Lounsbury, 1999). Humphreys, Post \& Ellis (1981) have provided a basic definition of Integration, "An integrated study is one in which children broadly explore knowledge in various subjects related to certain aspects of their environment. They further state that there are common skill sets to be learned in science, maths and English. Thus, Humphreys et al(1981) have stated two main components of integration ie merging similar skills sets in different disciplines where relevant and relating subjects with the environment in other words with world scenario. Similarly, Shoemaker (1989) too understands integration as combining elements of different disciplines together. He explains integration as cutting across "subject-matter lines, bringing together various aspects of the curriculum into meaningful association to focus upon broad areas of study." He is in agreement with Humphreys on the second component of integration as well that is relating to everyday life issues. In this regards, Shoemaker (1989) says that integrated curriculum "reflect the real world, which is interactive. The ideas of Humphreys and Shoemaker resonate in Pring's(1973) definition of integration as well. He states that integration is nothing but the "idea of unity between forms of knowledge and the respective disciplines". Several other scholars have attempted to explain integration as well. Noteworthy names include, Beane (1997) and Loepp (1999). Beane understands integration is an important tool to create meaningful learning organised with respect to relevant and serious every day issues. Hence Beane is also of the opinion that integrated currcilum ininvolves relating content with everu day life issues. Beane has suggested four aspects of integration namely, integration of experiences, social integration, integration of knowledge and integration of design. Beane explains that integration of experience is about integrating past and present experiences to facilitate new learning. Social integration is the result of students from diverse backgrounds enjoying common learning experiences. He further explains that, integration of knowledge is the product of content-area concepts integrating through a focus on relevant day to day serious issues. In this article, the focus is on the third category of integration i.e. integration of knowledge. Finally, Beane (1993) explains, that integration as a design stresses on project-based learning manly. Perhaps Loepp (1999) is referring to this very kind of integration when he mentions about the "problem-based" model of 
International Journal of Arts and Humanities

ISSN: 2581-3102

Volume: 04, Issue: 07 "July 2020"

integration. He explains that since we now live in a highly technological society we must make use of this tool when designing our curriculum. Loepp (1999) believes technology can help us better integrate two different subjects. He asserts,

"with a technological problem at the center, disciplines lend their support in helping to solve the problem. An example problem might be to determine how the waste produced in a community could be turned into an asset. In this instance, the social studies class can address the role of local government in collecting and disposing of waste; in science the emphasis could be on reducing materials to their basic elements and recombine them; and in mathematics one could study measurement, area, volume, and so forth. In technology education, the focus might be on the various technologies used to separate waste into categories as well as the transformation of waste into usable materials." (p.23)

It is contended that these three components of integration as explained by the scholars above are integral in understanding the meaning of integrated curriculum. These components are: merging common sets of skills, relating this knowledge to everyday life issues and encouraging project based learning in the classroom. After identifying these three requirements of integrated curriculum, it is believed that Al-Hidabi's (2019) definition of an integrated curriculum derived from Quranic methodology, checks all these three criteria in the secular definition of integrated curriculum. Hence this article will adhere to these three standards as suggested by secular scholars and Al-Hidabi(2019).

Having discussed what criterions help to define integration, it is necessary to also study the different types of integration and identify which categorization of integration is most relevant to this article. Drake and Reid (2018) have organised the views of integration and attempted to explain the four mains types of integration i.e. Fusion, Interdisciplinary, Multidisciplinary and Transdisciplinary. They state that fusion is the most basic method of integration. They explain that in Ontario, educators are required to infuse character education and financial literacy among others into mandated subject curriculum. A multidisciplinary curriculum features a similar theme or a common capability in different subject areas, but each subject is still distinct and separate. As they explain, "for example, the theme of "identity" could be explored in geography (mapping), history (nationality), literature (characterization), science (classification) and so on." An interdisciplinary curriculum occurs when skills such as inquiry or communication are taught across subject areas and the subjects are less distinct. For example, students could apply critical thinking to develop a social justice campaign around a local issue such as water quality or homelessness. A transdisciplinary curriculum transcends the disciplines; the organizing centre revolves around a pressing question, issue or problem. From these explanations, it can be stated 
International Journal of Arts and Humanities

ISSN: 2581-3102

Volume: 04, Issue: 07 "July 2020"

that fusion is the closest model of integration applied in this article. This is because the proposed model will benefit from the ideas of both Hassan(2010)'s and Al-Hidabi(2019)'s integration models that have spoken about integrating key concepts of Islamic worldview such as Taweed, Iman, Tafakkur, Tazkiyah while developing an integrated curriculum. Hence it can be said that the proposed model will attempt to infuse Hassan'(2010) Ulu al Baab features into the subject being Islamised or infusing Al-Hidabi's(2019) identified key components of IOK such as Sifat of Allah, Imar, Khalifah, and Akhlaq. It would not be wrong to state that future integrated Islamic curriculums can benefit from the multi-disciplinary approach as well. For example, the concept of Islamic Brotherhood can be explored in the IS subject and the GS subject as well when studying about Globalisation. However multi-disciplinary, interdisciplinary and transdisciplinary integration models require much more resources of time and planning which was not available. Hence this article has employed the model of fusion integration as explained by Drake and Reid. This aspect of integration can be deployed in this article as well. Hence the teachers can have students doing projects under the Humanities subject that require Islamic Perspective.

Discussion on integration is incomplete without discussing the views of Fogarty. Fogarty (1991) describes three basic categories of integrating the curriculum. Fogarty explains that integration can happen within a single discipline, across disciplines and within and across learners. Contained within these three categories are ten models of integration. Under the category of single discipline integration, he identifies three types of integration i.e. fragmented, connected and nested. When integration happens across disciplines, he identifies another five models namely, sequenced, shared, webbed, threaded and integrated. The connected model of integration suitably defines integration of Islamic Perspective in GP topic. Fogarty explains that the connected model provides a close up of the details and subtleties and interconnections within one discipline. The key to this model is the deliberate effort to relate ideas within one discipline rather than assuming that students will automatically understand the connections. Hence while Islamic Perspective is being taught in the IS topics such as charity and poverty, ablution and conservation of water, it is best to deliberately explain to students the Islamic Perspective in Poverty management or environmentalism instead of leaving it to the student to integrate it.

The sequenced model of integration under across disciplines is also a viable option but time consuming. It has been considered as a viable option because firstly, while not all GP topics would be discussed in IS class, almost all GP topics would have an Islamic Perspective and thus will be discussed in some manner in the IS class. Hence this is more of an integration across disciplines because content matter of two subjects is overlapping. Fogarty explains that under the sequential model, similar ideas are taught in concert although both subjects are separate. Hence if Zakat and charity is being taught in IS class, Unemployment and Poverty can be taught in GP class. As per the interviews with student, GP and IS teachers, this is already happening at times. 
International Journal of Arts and Humanities

ISSN: 2581-3102

Volume: 04, Issue: 07 "July 2020"

For instance, one student mentioned that after studying zakat and charity, it was followed by Unemployment and Poverty in the GP class. This method is more flexible and less time consuming than the shared integration approach under the across the disciplines category (Fogarty, 1991). Since, this article is about integrating the Islamic perspective into the GP subject in the TNG School, it is worth examining the IS subject being taught in parallel with GP subject. The shared model brings two distinct disciplines together into a single focus. The shared methodology overlaps concepts as the organizer. In this shared approach to integration it is necessary that the teachers of the two disciplines plan their teaching which will take place in the individual classes together. The two members of this "partnership" (possibly cross-departmental) plan the unit of study by focusing on common topics, concepts and skills. As the "team" identifies these commonalities, they identify overlaps in content. The partners should examine what concepts and skills the topics and unit(s) have in common. The problem with both sequential and shared integration models is that bought require a lot of meticulous planning and this this research could not afford it. While sequential is slightly more flexible in teaching similar topics simultaneously, this model is also not easy to implement unless there is a curriculum developer involved and must time is invested into this form of integration. Finally, within the third category of integration i.e. within learners and across learners, we have the "Immersed" integration which focuses all curricular content on interest and expertise. With this methodology, integration takes place within the learners, with little or no outside intervention. This integration methodology will not be helpful in our article because we cannot leave the education learning experience solely with student. The integration of the Islamic perspective is complex and students will need to be guided by carefully trained teachers. It seems that the shared model of integrating is less flexible than the sequenced model. However, the connected model of integration can be most viable for reasons explained above.

\section{Proposed Model of Integration of Islamic Perspective}

The proposed approach will be a mixed method that will borrow concepts from Al Hidabi's (2019) model, Baba et al (2015) QMIKE model, Hassan(2010) Ulu al Albaab model and AlAlwani'(1989) Eclectic Model, amongst other shcholars. These models have been explained and analysed in an earlier article. Finally, western theories of integration will also be incorporated where applicable such as the "Fusion Integration Method" discussed by Drake and Reid(2018) Fogarty's(1991) “Connected Model of Integration" (Fogarty, 1991), and Loepp's (1999) "Problem solving Project model." Therefore, below is the account of ideas and propositions borrowed from the above writers and thinkers.

\section{The Al-Hidabi Model of Integration}


International Journal of Arts and Humanities

ISSN: 2581-3102

Volume: 04, Issue: 07 "July 2020"

This model follows the Al-Hidabi's four phases model of integration adding just on more phase making it a total of five phases. In this regards, the four phases presented by Al-Hidabi are: Phase One (required knowledge to be acquired before writing Islamised textbook; Phase Two(writing Islamised textbook by integrating Islamic Perspective and key Islamic concepts and critically analysing secular content of textbook, Phase three: Seeking feedback from educationists of the concerned discipline, Phase four: Pilot testing the textbook. He proposed model will add a phase after phase two labelling it "treating secular knowledge". These five phases are central to the idea of integration in Islam. This is because until and unless textbook authors do not have a holistic understanding of IH in relation to their discipline, they cannot truly understand the Islamic Philosophy of the discipline. Hence, the first phase of integrated textbook writing by Al-Hidabi is extremely crucial and builds the first phase of the proposed integration model. The only modification in this context is that Al-Hidabi suggests that first knowledge from the related field must be studied and Muslim scholars and then revealed knowledge in this context and then critically evaluate. However it is argued that first the discipline should be identified and the subject name. Following this, the keywords and key concepts should be identified and then IH studied and analysed in this context of the keywords and key concepts to develop the philosophy and purpose behind teaching the discipline and the subject textbook. Thus review of secular philosophy and secular content related to the discipline and subject has been removed and will be placed in the third phase.

In Phase two, before moving to University goals, the criteria of observing the world is added. While this is an ongoing process and would have been initiated even before the reading of $\mathrm{IH}$, it is still intentionally placed in Phase two because there is a possibility that those textbook authors who graduated from secular backgrounds will observe the world from a secular philosophy. Hence, while observing the world is a natural phenomenon which cannot be paused, it can somewhat be re-observed in relation to the discipline and related subject after studying the IH in context of the identified keywords and key concepts. This will be dealt with in the third phase. The main criteria that Al-Hidabi has mentioned in Phase two are: 1) integrating Maqasid Shariah, University or school goals, academic programmes goals into the textbook; 2) Integrating secular accumulated knowledge where 3) Integrating revealed knowledge where relevant; 4) Integrating key concepts of tawheed, ibadah, tazkiyah, khalifa and imar, sifat of Allah and Akhlaq; 5) Relating textbook content with everyday life issues; 6) incorporating ICT. Regarding the first point, it is not enough to create general outcomes of the subject only. It is necessary that together with the general outcome of the subject, specific outcomes from each topic should be created so that teachers have a clear understanding why every specific topic in the GP Subject has been Islamised. Hence, it can be construed that the feature of OBE recommended by Zainuddin (2018) will be is similar to the what Al-Hidabi has argued in his model as the first step. Al-Hidai (2019) has stated that the aims and objectives of IOK, university 
International Journal of Arts and Humanities

ISSN: 2581-3102

Volume: 04, Issue: 07 "July 2020"

goals, even academic programmes be clearly visible and logically connected during the writing of the Islamised textbook. The first step of the proposed model draws from "The Outcome Based Approach" as created by William Spady (1994). This model states that first course objectives must be defined and then course content should be created based on the course objectives. Zainuddin(2018) has recommended that the Outcome Based Approach be used by those attempting to create Islamised learning materials for Muslims. It could not be agreed more and have made this the first step in creating an integration model. Without knowing exactly what kind of student we want to create from teaching a specific subject, how can we know what must be taught to transform the student into the ideal Islamic person we intent to make of the student? Hence, we suggest that instead of simply creating Islamic objectives for the whole curriculum and each course, Islamic objectives for each chapter or unit should be defined as well. IOK is an elusive concept and it's possible that if simply general Islamic objectives are defined, it won't help in individually and specifically Islamising every chapter of every textbook. While we have mentioned here that Islamic outcomes must be defined at the foremost, a question arises as to how we can come up with the Islamised outcomes. What are these Islamised Outcomes?

The proposed model incorporates all the points issued by Al-Hidabi except relying on secular knowledge and integrating relevant revealed knowledge where necessary. This is because the original text to be written will be based on revealed knowledge ie IH. As mentioned earlier, Hashim (2014) had suggested regarding the re-classification of knowledge and falling back on classical Muslims scholars from Al-Farabi to Ibn-Sina to many others. Infact, Hashim (2014) had demonstrated how the Iowa State University and IIUM universities educational priorities differed because of different epistemological backgrounds. Thus what may be necessary in secular GP textbook maybe unnecessary in an Islamic GP textbook and vice versa. Thus the reliance on secular body of knowledge for producing the first draft of an Islamised textbook should be avoided as much as possible. Thus, IH is the basis on which the two chapters have been authored. However integrating key concepts such as Imar, tazkiyah, Khalifah and others requires analysing the $\mathrm{IH}$ content and interpreting it to make students understand these concepts. Hence including them separately is acceptable and much needed. The only key concept to be added here is Ummah. The idea of one Muslim community must be inculcated in students.

Phase three:

The proposed model adds one new phase component here and lists three criteria.

Firstly, secular body of knowledge will be studied and their worldview critically analysed from the IOK perspective. Following this, the concerned textbooks from the secular textbooks can be analysed and ideas incorporated where dire necessary. Add frog part here. 
In the third phase and fourth phases, Al-Hidabi suggests that:

- Once the first draft of the textbooks is prepared, it has to be reviewed by subject specialists and educationalists. Then, the authors will improve their materials in light of the feedback of both specialists and educationalists.

Fourth phase:

- Piloting the textbooks developed and assessing the impact of its implementation. Then, authors have to improve it in the light of its piloting and evaluation. All materials have to be reviewed every four years to issue a new version to ensure updating it due to many factors.

Indeed feedback from educationists of the related discipline and pilot testing the Islamised textbook will address the issues that might have been overlooked by the author.

\section{The QMIKE Approach}

The QMIKE integration approach is teacher centered as the proposed model will be too. The main aspects of this approach are that teachers must be fully aware of the historical background of IOK and its importance in the revamping of the secular education model otherwise they cannot transfer the IOK spirit into their students. The second important aspect of this approach is that teachers must have Islamised teaching material beforehand. This means that the textbooks, slides, etc are already integrated with the Islamic worldview. There will be no such thing as teaching a student through a secular text book and then verbally providing an unsystematic adhoc perspective of Islam. Such practices as Abdallah et al (2011) points out only confuse students. The proposed model has taken this point home and will be using it as a central guiding light in the proposed model. The researcher believes that the QMIKE step of reading the Quran textually and contextually and taking lessons from and the Islamic heritage is a parallel process. Students need to read the Quran both textually and contextually and study the Islamic Heritage and compare this knowledge to the integrated subject knowledge in the classroom for comparative and more holistic learning. Hence this step should be an on ongoing process. Similarly a general and parallel training component for IOK and integration and teaching methodology should be implemented all through the year. This point was suggested by AlHidabi (2019) and is well taken.

\section{The Eclectic Approach}


International Journal of Arts and Humanities

ISSN: 2581-3102

Volume: 04, Issue: 07 "July 2020"

Eclectic Approach to integrate Islamic Perspective into the Humanities subject. The simplest explanation of integration is to make connections across disciplines (Drake \& Burns, 2004). There are three categories which offer a starting point for understanding different approaches to integration, namely the Multidisciplinary Approach, Interdisciplinary Approach and the Transdisciplinary Approach. It is found that the division boundaries between these three approaches fade away as curriculum developers plan, develop and implement these approaches (Drake and Burns 2004). It is important to study these approaches. However one needs to note that this research is not about integrating science and English subjects rather it is about integrating subjects with somewhat different if not opposing epistemological backgrounds. The epistemological background of the GP Subject in the TNG School in Qatar seems to be one which is Western centric. The researcher concluded this by observing that the chapter on Mughal History and the colonization of India by the East India Company were taught as a "value free" unit without providing students with an idea of an Ideal Islamic Empire and pitting it against the Mughal Empire resulting in its obvious colonization because the distance that the Mughal Empire creating between Islamic believes and practice. Thus the Eclectic approach seems to be most suited for integrating the Islamic perspective into the Humanities subject. But it fails to develop among students the urge and skills for creativity. The Eclectic Model is about selecting or employing different elements, already available, from a variety of sources and combining them (Al-Alwani, 1989). This approach contends one must select from traditional thought what is most sound and from modern contemporary thought that which is one considers to be correct and weld the two and form an intellectual structure which will provide a guaranteed basis for achieving what is required (Baba S. , 2013). It is a method that will come in handy but cannot be the foundational basis of a true integration practice.

\section{Fogarty's Connected Model}

According to this model, the GP teacher can integrate Islamic Perspective into every topic because every GP topic has an Islamic Perspective. It is not necessary to separate the Islamic Perspective and have it solely taught in the IS class. It can be taught directly in the GP class ensuring there is a higher possibility that student will understand the Islamic Perspective instead of teaching it as a sequential or shared model where the Islamic Perspective is taught in the IS class but just either before or after the GP class.

\section{Loepp's Problem Solving Method of integration}

As stated earlier, Project Based Problem Solving Method of Integration explained by Loepp (1999, explains that assigning students projects where they have to solve a problem, helps to integrate different subjects. The authors agree with Loepp that Problem Solving projects are one 
of the best ways to integrate subjects across disciplines. Loepp explained that assigning students projects where they have to solve a problem, helps to integrate different subjects. The authors have borrowed from this approach by instructing students to solve problems with an Islamic Perspective. However, time and resources factors did not allow the researcher the luxury to deploy such a grand integration model.

\section{Mother model of Integration}

This is the "mother model" of integration in others words the ideal model of integration. Based on the discussion above, the mother model of integration is presented:

\section{Phase One:}

1. Identify discipline. Let's say its GP which has replaced the term social studies in International Schools affiliated to Cambridge University. Since GP is a new term for social studies, it can be said it may partly fall in the discipline of sociology.

2. Identify keywords and central ideas of the subject. Now GP subject intends to not only teach about society and social issues but also political, economic and environmental issues. It also focusses on critical and independent thinking. Hence the keywords and central ideas here are: Sociology, society, social studies, politics, economics, environmentalism, critical thinking and independent thinking. There could be more but we can start working with this for now.

3. Study and analyse Islamic Heritage in relation to above keywords and develop its philosophy.

a. How are these keywords defined?

b. What is the etymology and lexicology of these terms?

c. How were these terms used before and after the advent of Quran?

i. This step can highlight the shift in the belief and attitude towards these terms.

d. What are the central themes?

e. What are the direct injunctions?

f. What are the indirect injunctions

4. Develop the philosophy of the discipline and the purpose behind teaching the discipline and related subject in school or university based on the above study of IH in relation to the keywords identified.

\section{Phase two:}


International Journal of Arts and Humanities

ISSN: 2581-3102

Volume: 04, Issue: 07 "July 2020"

5. Observe the world around you in all its dimensions be it people, technology, natural landscape, world events related to the identified key terms and central ideas. Exclude academic literature related to the keywords at this point.

6. Develop the syllabus structure for the subject from year one to ten, pre-university, bachelors, masters and $\mathrm{PhD}$ programmes based on the following criteria:

a. Developed Islamic Philosophy of Sociology

b. Developed Islamic Philosophy of GP subject and its related keywords and key concepts,

c. Observation of the world around you in relation to Sociology and GP subject,

d. Concerned university or concerned school higher goals(in this case the TNG School)

e. Concerned goals of the academic programme.

7. Write content for the textbook based on the above while keeping in mind a very important criteria of originality.

a. Textbook authors should be PhD scholars and have IOK trained students under their wing who can go into the field and do research on a given topic and the textbook author can develop the textbook based on his research team's input.

b. For example, when an IIUM author is writing a secondary school biology textbook, under the topic of dissecting animals, he/she can assign IIUM School secondary school biology teacher to simply tell students to dissect a frog and record their experiences. Even basic information about how to dissect a frog should not be provided. A student (not the teacher) should record the experiences which can then be used to write the topic on how to dissect a frog along with the integration of key Islamic concepts such as tawheed, imar, tazkiya, names of Allah and many more.

c. Such exercises may seem to be time consuming but are not. Secular schools students spend days in preparing for their prom night school activities and now in lower classes in figuring out their gender. Such time can be used in integrated Islamic schools for more hands on approach towards learning subjects. Exercises such as learning to figure out how to dissect a frog and record one's experience or in degree program to learn how to research without a secular textbook to guide on research methodology will inculcate independent and critical thinking in students. In fact, this model of teaching has already been established in several western schools where the job of the teacher is no longer to teach but to facilitate student's learning.

d. It must be pointed out here that such laboratory testing or first-hand field research to develop one's own research methodology must be conducted by the students as 
International Journal of Arts and Humanities

ISSN: 2581-3102

Volume: 04, Issue: 07 "July 2020"

they would first rely on their thinking rather than the textbook author who would most probably rely on what he has read about research methodology.

e. Integrate concept of sifat of Allah

f. Integrate key concepts of Tawheed, ibadah, Tazkiyah, khalifa, ummah and I'mar,

g. Relate topic to world real life issues

8. Study American, European, African, Asian, Hindu, Jewish, Christian philosophies of epistemology, metaphysics, ethics, politics and esthetics to critically understand their worldviews.

a. Textbook drafting is best done as a team for help in resources and integration of different ideas.

b. Hence team members could be assigned to study different philosophies.

9. Analyse American, European, African, Asian, Hindu, Jewish and Christian textbooks on the related subject in this case GP textbook.

10. Critically evaluate these textbooks content and incorporate their ideas only where dire necessary but after it has passed through the IOK filter.

a. Many times IOK educationists maybe saying the same thing but with different intentions. For example keeping both IOK and secular textbooks may state that in production we must keep costs to the minimum. Here the reason behind keeping low costs will differ. To the secular textbook write it is chiefly for higher profit margins and secondly for consumer affordability which is again for the purpose of selling the product. However to the integrated textbook developer, low costs should be maintained primarily for lower prices so that people who need the product or service can have access to it. This is just one example of the subtle and yet crucial differences that separate secular and IOK paradigms of knowledges oceans apart.

11. Provide critical analysis on secular perspective after incorporating it in textbook.

\section{Phase three:}

12. Seek feedback from integrated curriculum educationists' expert in the concerned field and subject content. Revise textbooks accordingly.

13. Train the teachers on how to use Islamised textbook

\section{Phase four:}

14. Pilot test and assess students and teacher's understanding in Islamic Perspective in concerned subject and topics. 
International Journal of Arts and Humanities

ISSN: 2581-3102

Volume: 04, Issue: 07 "July 2020"

This article has adopted certain components and criteria from the mother model and developed a process. The "child model" presented below was used for this article:

\section{The Child Model: Components, Criteria and Processes}

For the purpose of this article, an improvised version of the mother model was employed to integrate Islamic Perspective into two chapter of the GP textbook. The integration exercise using the Child Model is presented below.

\section{Example 1: Chapter: Single Family Unit Vs Extended Family Unit}

\section{Phase One:}

1. Identify keywords and central ideas of the subject.

a. The GP teacher was due to teach after a couple of weeks two chapter. One chapter was titled Single Family Unit vs Extended Family Unit where the teacher was going to discuss with students which form of family type is better. The second chapter was titled as, "How to evaluate a claim". In this chapter, the teacher was going to discuss with students on why a claim should be evaluated and what the process of evaluating a claim is.

b. Thus for first chapter, "Single Family Unit vs Extended Family Unit", the following keywords were identified: "family, duties towards parents, responsibility towards wife, responsibility towards husband', Muslim women living with in-laws, an ideal Muslim family,"

c. For the second chapter, "How to evaluate a claim", the following keywords were identified: claim, evaluating a claim, criterion for establishing a fact, reason, observation, experimentation.

2. Study and analysis of IH interms of first chapter keywords revealed the following the central ideas:

a. Children have responsibility towards parents even after reaching adulthood and marriage.

b. Wife has right to demand a separate accommodation from husband parent and relatives.

c. Wife has right for privacy due to the issue of hijab especially if there are non mahram men in the household of the husband.

d. Peace, love and understanding between husband and wife is fundamental and its disruption can cause several personal and social ills to grow.

3. Develop the philosophy behind teaching Single Family Vs Extended Family from Islamic Perspective. 
International Journal of Arts and Humanities

ISSN: 2581-3102

Volume: 04, Issue: 07 "July 2020"

a. The main ideas regarding single and extended family from Islamic Perspective demonstrated that the decision to select a form of family system depended on four main things: 1) responsibility of the son towards his parents and 2) the right of the wife to demand a separate place for accommodation due to privacy and hijab issues, 3) safe-guarding husband and wife relationship and 4)keeping family ties strong.

b. Hence the purpose of teaching Single Family Vs Extended Family article, should be discuss the roles and responsibilities children have towards their parents after they are married and the rights spouses have towards one another and how to create reasonable balance between the two.

\section{Phase Two:}

4. Write content for the chapter with the following criteria keeping mind the above philosophy behind teaching the chapter:

a. State the objective behind learning the topic:

i. To help students understand duties laid down towards parents by Allah swt.

ii. To help students understand the duties of spouses towards one another in Islam.

iii. To help students select a family system that will allow them to look after their parents and yet fulfill responsibilities towards spouse.

b. Inform students what IH says about roles and responsibilities of married children towards their parents.

i. Provide financial support

ii. Provide medical support

iii. Provide emotional support

iv. Perform mundane duties on their behalf that they cannot do themselves because of old age like paying bills, taking to clinic etc.

v. Extreme kindness to parents

c. Inform students about the duties of spouses towards one another.

i. Selected rights of wife

1. Right to food, shelter, clothing

2. Right to live separately

3. Privacy and hijab

4. Cannot be coerced to look after in laws

5. Respect and kindness

6. Not to be harmed 
ii. Selected rights of husband

1. Respect and kindness

2. Not to be harmed

3. Protect property when husband is away

d. Facilitate a discussion between the students about living in single family vs extended family in light of the Islamic information provided above.

e. Provide two articles to read on Single Family Vs Extended Family in Islam that has integrated key concepts such as sifat of Aallah, tawheed, khalifa, tazkiyah and imar wherever possible and relevant.The two articles selected in this regards were:

i. https://aljumuah.com/the-joint-family-system-an-assessment/

ii. https://thecompanion.in/on-joint-family-system-in-islam/

5. Study and Analyse secular textbook on this topic. During analysis of the Cambridge GP textbook on Single Family Vs Extended Family, it was observed that it was teaching the topic only materialistic aspect i.e. which system of family is most cost effective and more convenient.

a. The content analysed listed four benefits of living in extended family and two non-benefits;

i. Benefits of living in extended family

1. Less expenses in terms of rent, utility bills

2. Child care by grandparents is more reliable if couple have children

3. Children can tend to proper and immediate care to elderly parents or parents with special need if living under one roof.

4. Children are more social as they live with relatives of different generations.

ii. Non Benefits

1. Lack of privacy and space

2. Control and interference

b. Out of the four benefits mentioned one is outwardly materialistic in nature and the remaining three are also in subtle terms against the Islamic Spirit. This is because the Islamic Perspective dictates that the decision to live in single or extended family must first consider the duties towards parents and rights of spouses and peace within family. After these points are addressed, material issues can also be considered such as expenses etc. Secondly, the three benefits mentioned are all keeping the convenience of the married child in sight. Hence the content is indirectly telling the student to opt for extended family not because they have a responsibility towards their parents but because it is more convenient for them 
International Journal of Arts and Humanities

ISSN: 2581-3102

Volume: 04, Issue: 07 "July 2020"

and will benefit their young kids as well because they will be social living with different generations.

c. In this instance there is literally no need to incorporate any content from the school textbook because the issues of cost and convenience also occurred in the Islamic literature provided but were addressed with the Islamic worldview in mind. Since there was NO dire need of incorporating these ideas, it could be avoided. This was the original plan but the GP teacher did play a multimedia video from the secular perspective that stated the benefits and non-benefit of living in extended family from secular perspective.

d. A critical analysis was provided on the secular perspective of Single family vs Extended Family topic.

\section{Phase three:}

6. The integrated Islamic learning material on Single Family Vs Extended Family together with the model was provided to the GP teacher and Islamic studies teachers. The GP teacher suggested two things

a. Rights of physical intimacy between spouses was not appropriate for Grade 8 students.

b. Time period must be taken account because earlier only secular benefits and non benefits of living in an extended family was to be discussed.

c. However now, Islamic Perspective was also integrated which meant more time would be required.

d. Keeping this in mind the learning material was trimmed with removing several rights of spouses and limiting it to three to five most important rights.

\section{Phase four:}

7. This Islamised learning material based on the integration model was deployed in the classroom and six students, two GP teachers, two IS teachers and one principal were interviewed before deploying this model and after deploying this model to gauge their understanding of Islamic Perspective in the the topic of Single Family Vs extended Family.

a. Students were grouped into teams and asked to relate what they hsve learn with real life observations from their own family experience or those they have seen.

b. Students were asked to write an essay. The earlier essay title coined by the GP teacher was, "Is living with extended family members under one roof an ideal 
International Journal of Arts and Humanities

ISSN: 2581-3102

Volume: 04, Issue: 07 "July 2020"

form of living" to "Is living with extended family members under one roof an ideal form of living in Islam?"

\section{Example 2: Chapter: Evaluating Claims}

\section{Phase One:}

1. Identify keywords and central ideas of the subject.

a. The second chapter was titled as, "Evaluating claims". In this chapter, the teacher was going to discuss with students on why a claim should be evaluated and what the process of evaluating a claim is.

b. Thus for the second chapter, "Evaluating claims", the following keywords were identified: claim, evaluating a claim, criterion for establishing a fact, reason, observation, experimentation.

2. Study and analysis of IH interms of first chapter keywords revealed the following the central ideas:

a. Quran is the book of Allah swt and everything in it is true.

b. Authentic hadith is completely reliable.

c. Quran stresses on providing "proof" in scripture regarding claims made about God.

d. Quran stresses on observing the nature to see the signs of God.

e. Quran cites the importance of using reason in various verses.

f. Hadith reported that one should double check after hearing any statement or rumour.

g. Islamic Scholars like Imam Abu Hanifa have not trusted hadith from people with character defects like lying, gambling, etc.

3. Develop the philosophy behind teaching "Evaluating Claims" from Islamic Perspective.

a. To help students understand the importance of evaluating a claim.

i. Believers, if a troublemaker brings you news, check it first, in case you wrong others unwittingly and later regret what you have done (49:6)

ii. Ibn al-Haytham who is considered by many to be the first Muslim scientist wrote, "The duty of the man who investigates the writings of scientists, if learning the truth is his goal, is to make himself an enemy of all that he reads, and... attack it from every side," he wrote. "He should also suspect himself as he performs his critical examination of it, so that he may avoid falling into either prejudice or leniency." 
International Journal of Arts and Humanities

ISSN: 2581-3102

Volume: 04, Issue: 07 "July 2020"

b. To help students evaluate a claim through means of "revealed knowledge" i.e. Quran and Sunnah, Islamic Heritage, reason and observation.

\section{Phase Two:}

4. Write content for the chapter with the following criteria keeping mind the above philosophy behind teaching the chapter:

a. State the objective behind learning the topic:

i. To help students understand the importance of evaluating a claim.

ii. To help students evaluate a claim through means of "revealed knowledge" i.e. Quran and Sunnah, Islamic Heritage, reason and observation.

b. Th greatest claim anyone can make in the world is that, "I am God". Quran teaches us three methods to evaluate such a claim and even subjects itself to these three criteria. These three standards of evaluating a claim according to Quran are: 1) Reason, 2) Observation and 3) Experimentation.

c. Regarding the first criteria ie reason, Quran presents the following verses:

i. How can God have a son if he never had a companion"

ii. 39:5 He created the heavens and the earth with reason.

iii. 13:4. On earth are adjacent terrains, and gardens of vines, and crops, and date-palms, from the same root or from distinct roots, irrigated with the same water. We make some taste better than others. In that are proofs for people who reason.

iv. 45:5 And in the alternation of night and day, and in the sustenance God sends down from the sky, with which He revives the earth after its death, and in the circulation of the winds, are marvels for people who reason.

v. The worst of animals to God are the deaf and dumb - those who do not reason. (8:22)

d. Regarding observation, the Quran states:

i. And the people of Moses made, after [his departure], from their ornaments a calf that lowed [and called it God]. Did they not see that it could neither speak to them nor guide them to a way? They took it [for worship], and they were wrongdoers.

ii. 16:79. Have they not seen the birds, flying in the midst of the sky? None sustains them except God. In this are signs for people who believe.

iii. 22:46. Have they not journeyed in the land, and had minds to reason with, or ears to listen with? It is not the eyes that go blind, but it is the hearts, within the chests, that go blind.

e. Regarding experimentation, the Quran says: 
International Journal of Arts and Humanities

ISSN: 2581-3102

Volume: 04, Issue: 07 "July 2020"

i. "[7:194] The idols you invoke besides GOD are creatures like you. Go ahead and call upon them; let them respond to you, if you are right."

f. Provide one articles to read on "Evaluating Claims" in Islam that has integrated key concepts such as sifat of Aallah, tawheed, khalifa, tazkiyah and imar wherever possible and relevant.The two articles selected in this regards were:

i. http://aboutislam.net/counseling/ask-about-islam/blind-faith-criticalthinking/

g. Students were asked to team in groups and provide examples of real life instances of hearing or reading a claim and evaluating it.

5. Study and Analyse secular textbook on this topic. During analysis of the Cambridge GP textbook on "Evaluating Claims" it was observed that the purpose behind teaching the concept was to safeguard people's interest as a false claim can harm a person and to provide means of evaluating a claim. All points (check the source, use reason, observation and experimentation) raised in the textbook were covered by the author and it did not seem necessary to incorporate any idea from the GP textbook.

a. When the GP content was analysed it was observed that the textbook is providing claim examples such as, "Burj Khalifa is the tallest tower in the world", "It takes $\mathrm{X}$ amount of minutes to reach to $\mathrm{Y}$ destination through $\mathrm{Z}$ means of transport". It wasnoted that while the textbook is encouraging students to evaluate mundane claim, it is silent on the biggest and most crucial claim of i.e. when someone claim that $\mathrm{He}$ is God or that so and so is God. Is the textbook indirectly suggesting student to evaluate minor claims but use blind faith when reading or hearing a major claim?

\section{Phase Three:}

6. Seek feedback from GP teacher. The GP teacher had a difficult time teaching this topic with Islamic Perspective even after discussions with the researcher. This is because there were many questions that students were asking that th teacher was unable to answer from Islamic Perspective. Hence it was decided after the first class, that the researcher will teach in the beginning of the classes and once students are settled and comfortable with the Islamic Perspective in the topic, the teacher can take over.

\section{Phase Four:}

7. This Islamised learning material based on the integration model was deployed in the classroom and six students, two GP teachers, two IS teachers and one principal were 
International Journal of Arts and Humanities

ISSN: 2581-3102

Volume: 04, Issue: 07 "July 2020"

interviewed before deploying this model and after deploying this model to gauge their understanding of Islamic Perspective in the the topic of Evaluating Claims.

a. Students were grouped into teams and asked to relate what they hsve learn with real life observations from their own family experience or those they have seen.

b. Students were asked to write an essay. The earlier essay title coined by the GP teacher was, "How to evaluate claims in Islam?"

\section{Feedback on Integration Model}

The feedback on the integration model has been generally positive. One IIUM professor stated it's an "innovative model" while another stated that he was satisfied with the model and had "noting to add to it". The third professor also provided positive remarks. The TNG principal suggested that students should be involved in the creation of the integrated model but has overall provided positive feedback. The Islamic Studies and Global Perspectives teachers were also satisfied with the integrated model.

\section{CONCLUSION}

Western models of integrations as suggested by Beane(1997), Fogarty(1991) and Loepp(1999) and other scholars were also presented and analysed. Finally, the authors humbly proposed an integration approach based on the modified version of Al-Hidabi's(2019) model while incorporating ideas of various integration approaches by Muslim educationists and thinkers and using standard integration practices suggested by western educationists. Towards the end, the author demonstrated how the integration model could be used by integrating Islamic Perspective into two chapters from the GP textbook in the TNG School.

\section{BIBLIOGRAPHY}

Abdallah, S., Hussien, Suhailah, \& Ismail, N. A. (2011). The experience of Islamization of Knowledge at the International Islamic University Malaysia: successes and challenges. In Hussain, \& Suhaila, New Intellectual Horizons in Education. IIUM Press.

Al-Alwani, T. (1989). Islamic Thought: An Approach to Reform. International Islamic Institute of Thought.

Al-Hidabi, D. (2019). Integrating Islamic Perspective in textbooks. Presentation for Workshop by International Islamic Institute of Thought on Integrating Islamic Perspective in textbooks. 
International Journal of Arts and Humanities

ISSN: 2581-3102

Volume: 04, Issue: 07 "July 2020"

Al-Hidabi, D. (2019). Writing University Textbooks based on Integration. International Institute of Islamic Thought's(International Islamic University Malayisa Gombak Branch) Training Workshop on writing integrated textbooks .

Baba, S. B., Salleh, M. J., Zayed, T. M., \& Harris, R. (2015). A Qur'anic Methodology for Integrating. The American Journal of Islamic Social Sciences.

Beane, J. (1993). A middle school curriculum: From rhetoric to reality (2nd ed.). National Middle School Associa-tion.

Drake, R., J.L., \& Kolohon, W. (2014). Interweaving curriculum and classroom. Oxford University.

Drake, S. M., \& Burns, R. C. (2004). Meeting Standards Through Integrated Curriculum. ASCD.

Drake, S., \& Reid, J. (2018). Integrated Curriculum as an Effective Way to Teach 21st Century Capabilities. Asia Pacific Journal of Educational Research .

Fogarty, R. (1991). The Mindful School: How to Integrate the Curricula. Skylight Publishing.

Hashim, R. (2007). Intellectualism in Higher Islamic Traditional Studies: Implications for the Curriculum. American Journal of Islamic Social Sciences.

Hashim, R. (2014). Integrated Islamic Curriculum .

Hashim, R. (2014). Islamization of the Curriculum.

Hassan, M. K. (2010). A return to the Quranic paradigm of development and integrated knowledge: The Ulu al Albab model. Intellectual Discourse.

Humphreys, A., Post, T., \& Ellis, A. (1981). Interdisciplinary Methods: A Thematic Approach. Goodyear Publishing.

Loepp, F. (1999). Models of Curriculum Integration.

Nesin, G., \& Lounsbury, J. (1999). Curriculum Integration: Twenty Questions--with Answers. Georgia Middle School Association, Atlanta.

Pring, R. (1973). Curriculum Integration. In R. Peters, The Philosophy of Education. Oxford University Press. 
International Journal of Arts and Humanities

ISSN: 2581-3102

Volume: 04, Issue: 07 "July 2020"

Shoemaker, B. (1989). Integrative Education: A Curriculum for the Twenty-First Century. Oregon School Study.

Zainuddin, Z. (2018). Integration of Islamic Perspectives into Medical Imaging Curriculum: an Outcome Based Education Approach. International Medical Journal Malaysia. 